\title{
УТИЛИЗАЦИЯ НЕФТЕСОДЕРЖАЩИХ СТОЧНЫХ ВОД ЭМУЛЬГИРОВАНИЕМ И СЖИГАНИЕМ
}

\author{
Иванов Владимир Петрович1, \\ ivprem@tut.by
}

\author{
Дронченко Владимир Александрович1, \\ v.dronchenko@psu.by
}

Вигерина Татьяна Владимировна ${ }^{1}$, t.vigerina@psu.by

\author{
Пилипенко Станислав Владимирович1, \\ 44-08@mail.ru \\ 1 Полоцкий государственный университет, \\ Беларусь, 211440, г. Новополоцк, ул. П. Блохина, 29.
}

\begin{abstract}
Актуальность исследования обусловлена необходимостью разработки технологии и соответствующего оборудования для утилизации нефтесодержащих сточных вод, которые содержат растворы технических моющих средств, при исключении накопления их в значительных объемах в условиях отдельных ремонтных предприятий средней и малой мощности.

Цель: исключить загрязнение почвы и водного бассейна нефтесодержащими сточньми водами с растворами технических моющих средств, уменьшить долю выбросов вредных веществ в окружающую среду в ходе утилизации рассматриваемых отходов производства в промышленных котельных установках.

Методы: теоретические исследования процессов сжигания нефтесодержащих сточных вод с включениями растворов технических моющих средств; экспериментальные исследования процесса термической утилизации данного вида загрязняющих веществ методом сжигания их вместе с природным газом (либо печным топливом) на действующем промышленной паровом котле, с номинальным производством пара в 6,5 m/4.

Результаты. Разработана и предложена к использованию эфффективная (как с экологической, так и с экономической точки зрения) технология и оборудование для хранения и переработки сточных вод с нефтесодержащими отходами и их последующей утилизации методом сжигания вместе с природным газом (либо печным топливом) в действующем промышленном паровом котле. Наличие в топливе воды (около 10 \%) увеличивает эфффективность его сгорания, уменьшая выбросы оксидов азота в окружающую среду. Изучены особенности механизмов превращений, которые происходят при образовании капель водотопливной эмульсии и их последующем сжигании. Использование выделенного из нефтесодержащих сточных вод энергоресурса позволяет уменьшить потребление котельного топлива на 3-5\%.
\end{abstract}

\section{Ключевые слова:}

Нефтесодержащие сточные воды, эмульгирование, утилизация, сжигание, выбросы в окружающую среду.

\section{Введение}

Многие ремонтные предприятия сталкиваются с проблемой утилизации сточных вод, которые загрязнены нефтесодержащими продуктами (ЗНСП). Основные источники данного вида загрязнителей окружающей среды - это участки разборки и очистки агрегатов, участки восстановления деталей, обкаточно-испытательные, моечные и другие, связанные с основным направлением деятельности предприятия участки. Таким образом, на протяжении года на отдельном ремонтном предприятии образуется до одной тысячи тонн ЗНСП. В сточной воде таких предприятий содержатся частицы консистентных смазок, моторных и трансмиссионных масел, смазочноохлаждающих, промывочных жидкостей и др. [1-3]. Участок разборки агрегатов является одним из самых больших источников ЗНСП предприятия. На нем особенное место занимает разборка двигателей, в этом случае ЗНСП содержат до $65 . .90 \%$ моторных масел, около $6 \ldots 10 \%$ трансмиссионных, остальное приходится на топливные фракции и консистентные смазки.

Сточные воды с небольшим процентом загрязнений в виде технических моющих средств (ТМС) являются умеренно токсичными, однако при их накоплении уровень загрязнён- ности (особенно нефтепродуктами) повышается и они становятся не только токсичными, но и пожароопасными $[4,5]$.

Водные стоки промышленных предприятий по своим свойствам и химическому составу имеют значительные отличия от своего исходного состояния. Воды отражают в себе все множество технологических операций, в которых они использовались. Так, массосодержание нефтесодержащих загрязнителей и взвешенных веществ может достигать 1100 мг/л. Изначально почти нерастворимые в воде минеральные масла в такого типа стоках содержатся в виде устойчивых масляных эмульсий. Эти эмульсии образуются из-за мелкодисперсности масляных загрязнителей при наличии некоторого процента эмульгаторов [6-9].

Перед сбросом (или дальнейшим применением) ЗНСП воды должны пройти определенного вида обработку (химическую, биохимическую, термообработку и др.). В первую очередь должна быть проведена механическая очистка, включающая операции процеживания, отстаивания и фильтрования. Но в результате проведения ряда операций очищения остается некоторое количество остатков, которые можно только утилизировать.

В составе большинства предприятий имеются котельные, которые потребляют одно из видов твердого (дрова 
и древесные отходы), жидкого (мазут или печное топливо) или газообразного топлива. Сжигание любого вида топлива сопровождается выбросами в атмосферу оксидов углерода (II), азота, серы и др. вредных соединений. Без определенного вида модернизации оборудования котельных допустимые нормы выбросов могут превышаться в полтора-два раза [10-13].

\section{Выделение нерешенного}

Одним из комплексных решений вышеперечисленных экологических проблем может стать использование при утилизации ЗНСП с растворами ТМС процесса сжигания. При этом ЗНСП с растворами ТМС должны поставляться для сжигания в виде эмульсии фракции загрязнителей, частиц воды (размер до 10...20 мкм) и природного газа $[9,14,15]$.

В процессе сжигания такой эмульсии ее капли, нагреваясь до температуры кипения содержащейся в ней воды, под действием выделяемого водяного пара разрываются на множество фрагментов. В результате увеличивается площадь контакта частиц сжигаемой смеси с кислородом и процесс сгорания происходит более эффективно. Из-за присутствия воды температура факела снижается. Это приводит к снижению процентного содержания $\mathrm{NO}_{\mathrm{x}}$ в выходящих газах (образование $\mathrm{NO}_{\mathrm{x}}$ происходит при больших значениях температуры). Таким образом, разработка экономически эффективной технологии такой утилизации ЗНСП с растворами ТМС является актуальной проблемой.

\section{Объект и предмет исследования}

Объектом исследования выступает оборудование для переработки вод ЗНСП с растворами ТМС с целью их утилизации. Предметы исследования - механизмы и процессы трансформации небезопасных отходов в неопасное состояние.

\section{Основная часть}

Основная проблема, возникающая при подготовке такого типа загрязнителей к сжиганию, - разрушение поверхности контакта двух, казалось бы, несмешивающихся жидкостей. Тут необходимо создать условия, при которых произойдет нарушение гидродинамической устойчивости течения такого типа жидкостей [16-19]. Процесс сжигания с природным газом или жидким котельным топливом уже подготовленных к обезвреживанию нефтесодержащих загрязнителей (в виде эмульсии) происходит в топке котла, при этом распределение воды по объему эмульсии должно быть как можно более равномерным. Подготовка нефтесодержащих загрязнителей к сжиганию происходит в промышленных диспергаторах. Важным является то, что по естественным причинам срок хранения такого типа эмульсии ограничен одной неделей [2024]. Этого срока недостаточно для коммерческого использования эмульсии в качестве товарного продукта и постоянно возникают потребности к его увеличению.

Предлагается утилизировать воды, содержащие ЗНСП с растворами ТМС, согласно технологии, которая описана схемой, показанной на рис. 1. Результатом процесса утилизации является готовый к использованию вторичный энергоресурс. На рис. 2 показана принципиальная схема установки, которая разработана специально для проведения процесса утилизации вод ЗНСП с растворами TMC. Установка работает следующим образом. Не пригодные к дальнейшей очистке сточные воды поступают в емкость - 1 для отстаивания. Нижний патрубок с краном в этой емкости служит для слива излишков отстоявшейся воды. Отстоявшийся загрязнитель из первой емкости с помощью специального насоса - 2 перекачивается в емкость - 3. Эта емкость служит для приготовления эмульсии, для этого она оборудована пневматическим излучателем - 4. Готовая эмульсия хранится в последнем баке -5 .

Перерабатывающая станция использует ударноволновую технологию эмульгирования, которая позволяет производить переработку труднорастворимых компонентов с помощью ударных волн низкой частоты $[14,17]$.

Стабильность состояния эмульсии на протяжении длительного периода времени достигается тем, что при использовании в приготовлении эмульсии пневмоизлучателя, генерирующего волны низкой частоты, достигается значительное уменьшение размеров капель воды, естественным образом остающейся в составе эмульсии (рис. 3). Практика показывает, что содержание воды в эмульсии колеблется в границах 10-15\%.

Частота выхлопов сжатого воздуха зависит от расхода воздуха. Выхлоп сжатого воздуха (на глубине $0,45 \ldots 0,75$ м) приводит к образованию воздушной полости, всплывая, она резко расширяется, совершая до четырех пульсаций с затухающей амплитудой. Затем воздушный пузырь схлопывается. При этом из-за физических свойств жидкости давление на фронте схлопывающегося пузыря превышает давление в излучателе в 2,5...3,0 раза. Большая часть жидкости перемешивается всплывающими пузырьками. При расслоении эмульсии (из-за длительного хранения) обработку повторяют.

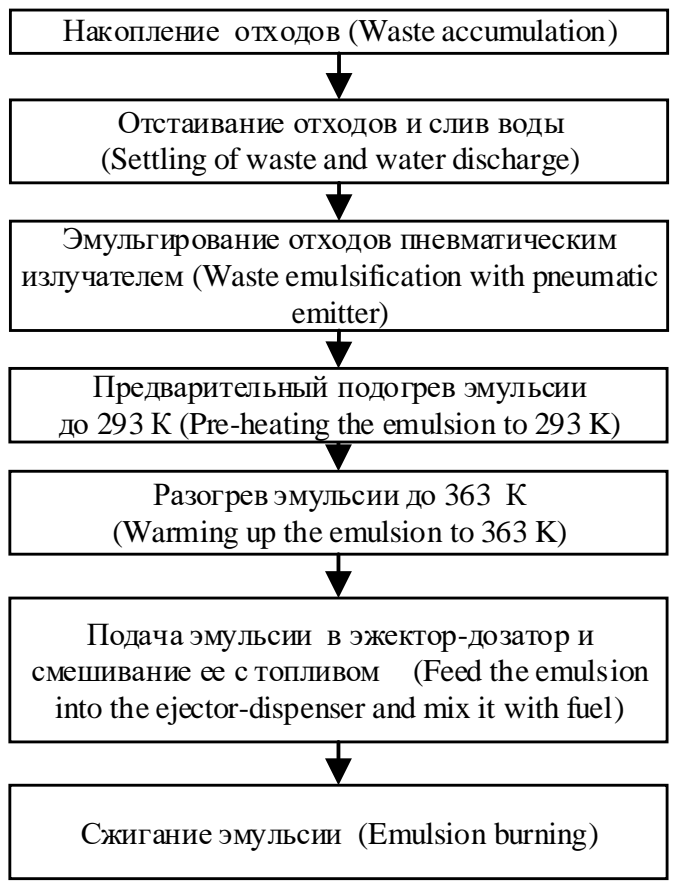

Рис. 1. Схема технологии утилизации вод ЗНСП с растворами ТМС, непригодных к дальнейшей очистке

Fig. 1. Scheme of water-fuel emulsion preparation and its combustion in a steam boiler 


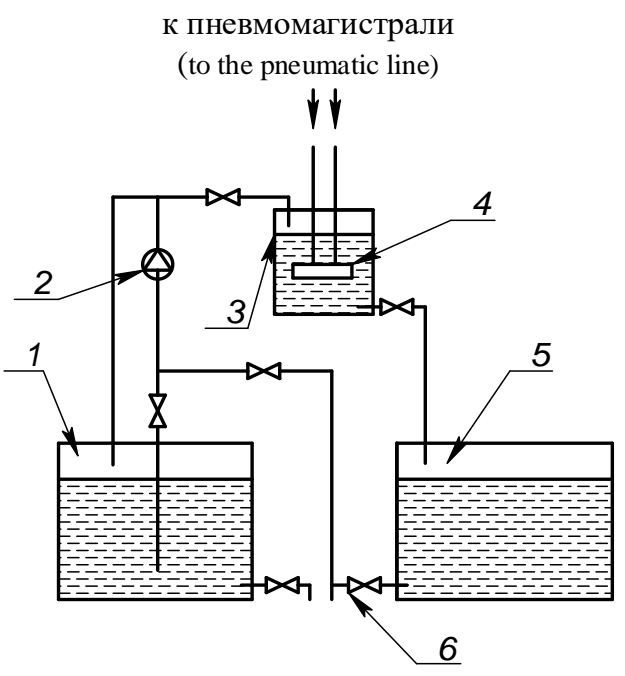

Рис. 2. Принципиальная схема станщии изготовления вторичного энергоресурса утилизачией вод ЗНСП с растворами ТМС, непригодных $\kappa$ дальнейшей очистке: 1 - емкость для отстаивания; 2 - насос; 3 - емкость приготовления эмульсии; 4 - пневмоизлучатель; 5 - бак готовой эмульсии; 6-кран

Fig. 2. Diagram of installation for production of secondary energy: 1 is the tank for sewage settling; 2 is the pump; 3 is the working capacity; 4 is the pneumatic radiator; 5 is the tank assembly; 6 is the valve

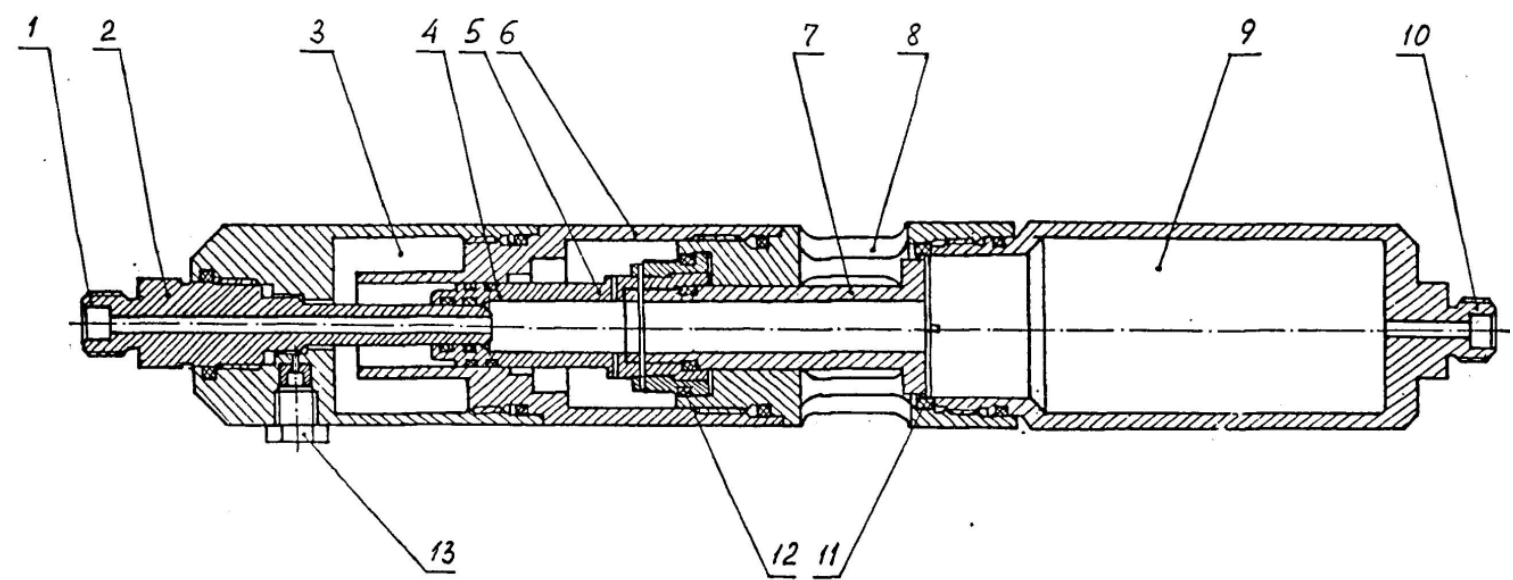

Рис. 3. Пневмоизлучатель: 1, 10 - штуиер; 2 - золотник; 3 - полость демпферная; 4 -пориень; 5 -хвостовик; 6 - переходник; 7 - поршень двухфланцевый; 8-окно; 9-ресивер; 11, 12 - уплотнительные кольца; 13 - заглушка

Fig. 3. Pneumatic radiator: 1,10 are the unions; 2 is the spool; 3 is the damping cavity; 4 is the annular piston; 5 is the shank; 6 is the adapter; 7 is the two-flange piston; 8 is the window; 9 is the receiver; 11, 12 are the sealing rings; 13 is the plug

В котельную подают предварительно подогретую жидкость до 293 К (что актуально в холодное время года, т. к. емкость для ее хранения находится снаружи здания). Перед непосредственным использованием эмульсия подогревается до 363 К. Эмульсия подается струей (смесь эмульсии, воздуха и топлива) через эжектор-дозатор. В зависимости от изменения расхода топлива необходимое соотношение «эмульсия-топливо» регулируется автоматикой. Смесь «эмульсия-топливо» через эжектордозатор поступает в форсунку топки котла. Стабильность эмульсии зависит от размеров капель дисперсной фазы (воды), а они, в свою очередь, - от времени действия пневмоизлучателя.

Отстоявшийся загрязнитель обрабатывают пневмоизлучателем интенсивно, в течение 12-15 минут, далее процесс эмульгирования видимого эффекта не приносит.

Долю выделенной воды $Q(\%)$ в зависимости от времени работы пневмоизлучателя и времени отстаивания можно рассчитать согласно выведенной регрессионной зависимости:

$$
Q=21,527-2,403 t_{\text {п.и }}+0,076 t_{\text {п.и }}^{2}+0,377 t_{\mathrm{x}},
$$

где $t_{\text {п.и }}$ - время работы пневмоизлучателя, мин; $t_{\mathrm{x}}-$ время отстаивания эмульсии, сутки.
Производная от функции (1) по времени работы пневмоизлучателя имеет вид:

$$
d Q / d t_{\text {п.и }}=-2,403+0,152 t_{\text {п.и }} .
$$

Приравняв правую часть уравнения (2) к нулю, находится оптимальное время работы пневмоизлучателя, составляющее $t_{\text {п.и }}=15,81$ мин. Для качественной работы пневмоизлучателя необходимо обеспечивать непрерывную подачу сжатого воздуха с давлением в 0,4 ...0,6 МПа. При частоте работы пневмоизлучателя в 2 Гц достигается лучший эффект воздействия пневмоизлучателя при достаточной величине мощности каждого удара. Размеры капель воды при этом составляют 10...20 мкм.

Когда известно оптимальное время приготовления эмульсии, можно определить ту долю исходно содержащейся в отходах воды, которая будет выделена при расслаивании (в результате отстаивания объем выделившейся воды не должен превышать 2 \%). В результате проведения ряда опытов по эмульгированию в течение 20 минут нефтесодержащих отходов, варьированным фактором в которых было процентное соотношение в отходах воды, получено линейное уравнение регрессии, позволяющее вычислить долю выделенной из эмульсии воды $(Q)$ при известном исходном содержании жидкости в стоке и времени его хранения: 


$$
Q=63,072-0,863 Q_{\text {нс. }}+0,221 t_{\mathrm{x}} \text {, }
$$

где $Q_{\text {нс. }}$ - исходный процентный объем нефтесодержащих отходов в эмульсии, \%.

На основании расчета по формуле (3) и результатов эксперимента установлено, что после 30 суток отстаивания эмульсии с содержанием воды $15 \%$ выделяется не более $2 \%$ воды (при температуре $291 \mathrm{~K}$ ).

Также проведены исследования утилизации рассматриваемого вида отходов промышленности (обработанных описанным выше методом) путем сжигания вместе с природным газом на действующем паровом котле марки ДКВР6.5-13, с номинальной паропроизводительностью 6,5 т/ч, вырабатывающем пар с давлением 1,26 МПа. В составе оборудования присутствует экономайзер ЭП-1-330 и дутьевой вентилятор ВД-10. Доказано, что получаемый в результате предложенной технологии утилизации вторичный энергоресурс сравним по теплотворной способности с печным топливом и природным газом (таблица).

Таблица. Теплотворная способность и элементный состав вторичного энергоресурса и традиционного котельного топлива

Table. Calorific value and elemental composition of the secondary energy source and traditional boiler fuel

\begin{tabular}{|c|c|c|c|c|c|c|}
\hline \multirow{3}{*}{$\begin{array}{l}\text { Вид топлива } \\
\text { Type of fuel }\end{array}$} & \multirow[t]{2}{*}{$\mathrm{H}$} & \multirow[t]{2}{*}{$\mathrm{N}$} & \multirow[t]{2}{*}{ C } & \multirow[t]{2}{*}{ S } & \multicolumn{2}{|c|}{$\begin{array}{c}\text { Теплотворная } \\
\text { способность } \\
\text { Calorific value }\end{array}$} \\
\hline & & & & & \multirow{2}{*}{ 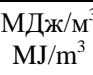 } & \multirow{2}{*}{$\begin{array}{l}\text { МДж/КІ } \\
\mathrm{MJ} / \mathrm{kg}\end{array}$} \\
\hline & & & $\%$ & & & \\
\hline $\begin{array}{l}\text { Топливо печное } \\
\text { Stove fuel }\end{array}$ & 9,5 & 0,3 & 79,5 & $0,5 \ldots 1,1$ & - & 39,5 \\
\hline $\begin{array}{l}\text { Природный газ } \\
\text { Natural gas }\end{array}$ & 23,5 & $0,5 \ldots 3,5$ & 72,5 & $0 \ldots 0,3$ & 33,5 & - \\
\hline $\begin{array}{l}\text { Вторичный энергоресурс } \\
\text { Secondary energy }\end{array}$ & 9,8 & 0,27 & 80,2 & 0,4 & - & 41,0 \\
\hline
\end{tabular}

Процесс теплопередачи, наблюдаемый при сжигании капель эмульсии вместе с традиционным котельным топливом, можно описать уравнением

$$
\gamma\left(T_{\mathrm{r}}-T_{\mathrm{cp}}\right)=\lambda \frac{\partial T_{\mathrm{cp}}}{\partial r}-\rho q \frac{\mathrm{d} r}{\mathrm{~d} t},
$$

где $\gamma$ - коэффициент теплоотдачи; $T_{\text {г }}$ - температура среды, примыкающей к капле; $T_{\mathrm{cp}}$ - средняя температура среды в капле; $\lambda$ - коэффициент теплопроводности среды в капле; $q$ - удельная теплота испарения эмульсии; $r$ мгновенный радиус капли; $\rho$ - плотность среды в капле.

Предложена математическая модель горения капли эмульсии, учитывающая несколько срывов оболочки капли, в которой температура $T_{1}$ является критерием прекращения срыва контактирующего слоя. В этом случае уравнение (4) принимает вид

$$
\frac{d r}{d t}=\frac{1+k\left(T_{\mathrm{cp}}-T_{1}\right)}{\rho q}\left[\lambda \frac{\partial T_{\mathrm{cp}}}{\partial r}-\gamma\left(T_{\Gamma}-T_{\mathrm{cp}}\right)\right]
$$

\section{СПИСОК ЛИТЕРАТУРЫ}

1. Mazumder D., Mukherjee S. Treatment of Automobile Service Station Wastewater by Coagulation and Activated Sludge Process international // Journal of Environmental Science and Development. - 2011. - V. 2. - № 1. - P. 64-69.

2. Thermochemical processing of sewage sludge to energy and fuel Fundamentals, challenges and considerations / S.A.S. Syed, W. Yi, H. Song, S. Sheng, X. Jun // Renewable and Sustainable Energy Review. - 2017. - № 80. - P. 888-913. где $r$ - радиус капли, м; $k$ - коэффициент, учитывающий скорость разрушения контактирующего слоя капли. Формула (5) позволяет установить зависимость изменения радиуса капли эмульсии $r$ от времени $t$ в процессе ее горения.

Кроме вышеперечисленного, исследовались вопросы, связанные с определением влияния различных режимов работы котельного агрегата и состава сжигаемого топлива на образование оксидов азота. Варьируемыми факторами являлись:

- содержание воды ( $w=0-25 \%$ с шагом в $5 \%$ ) в эмульсии (определялась также температура факела, величина расхода традиционного топлива);

- коэффициент избытка воздуха $(\alpha=1,05-1,20$ с шагом в $0,05)$ (изменялась и нагрузка котла: $M=50,75,100 \%$ ).

Опыты проводили по четыре раза. Получены следующие результаты: при увеличении влагосодержания от 0 до 25 \% происходило снижение температуры факела котла на $100 \ldots 150 \mathrm{~K}$, уменьшается длина факела, при этом содержание $\mathrm{NO}_{x}$ уменьшается с 250 до $150 \mathrm{Mr} / \mathrm{M}^{3}$.

С целью определения такого режима работы котла, при котором исключался бы химический недожог при наименьших выбросах окисей азота в окружающую среду, производились экспериментальные сжигания эмульсии с десятипроцентным содержанием воды вместе с традиционным котельным топливом. В результате получена регрессионная зависимость процентного содержания в выбросах окисей азота $\mathrm{NO}_{\mathrm{x}}$ в зависимости от коэффициента избытка воздуха $\alpha$ и мощности котла:

$$
\mathrm{NO}_{\mathrm{x}}=-2580,53+183,37 M+4269,83 \alpha-1716,67 \alpha^{2} .
$$

Согласно зависимости (6) со снижением $\alpha$ в дымовых газах падает концентрация $\mathrm{NO}_{x}$. Путем приравнивания к нулю производной от изменения части оксидов азота по коэффициенту избытка воздуха $d \mathrm{NO}_{x} / d \alpha=4269,833$ $2 \cdot 1716,67 \alpha=0$, определяем, что при номинальной нагрузке $\alpha=1,24$ имеется минимальное содержание $\mathrm{NO}_{x}$ в дымовых газах.

\section{Заключение}

Приготовление эмульсии на основе отработанных нефтесодержащих продуктов и ее сжигание с природным газом или печным топливом позволяет значительно уменьшить объемы накопления этих продуктов на предприятии. Повышение эффективности сжигания топлива и уменьшение выбросов оксидов азота достигается благодаря увеличению влагосодержания топлива. Экспериментальные исследования показали, что использование в качестве вторичного энергоресурса эмульсии уменьшает потребление природного газа или печного топлива до $5 \%$.

3. Opportunities and challenges in sustainable treatment and resource reuse of sewage sludge / R. Abdul, S.S. Vineet, H. Jun, D. Wafa, D.D. Dionysios, W. Wei, Z. Ming // Chemical Engineering Journal. 2018. - № 337. - P. 616-641.

4. Тельнов Н.Ф. Очистка машин и вопросы экологии // Механизация и электрификация сельского хозяйства. - 1996. - № 4. С. $36-41$.

5. Дронченко В.А. Использование отходов ремонтного производства в качестве технологических материалов // Труды ГОСНИТИ. 2017. - T. 126. - C. 117-120. 
6. Zaneti R.N., Etchepare R., Rubio J. Car wash wastewater treatment and water reuse - a case study // Water Science \& Technology. 2013. - № 67.1. - P. 82-86.

7. Identifying improvements in water management of bus-washing stations in Brazil / C.M.V.B. Almeida, D. Borges, S.H. Bonilla, B.F. Giannetti // Resources, Conservation and Recycling. - 2010. № 54 (11). - P. 821-831.

8. Climbing the ladder: a step by step approach to international guidelines for water recycling / J. Anderson, A. Adin, J. Crook, C. Davis, R. Hultquist, C. Jimenez // Water Science and Technology. - 2001. - № 43 (10). - P. 1-8.

9. Дронченко В.А., Семенов В.И. Защита окружающей среды от вредного воздействия отработанных растворов, образующихся при погружной очистке машин и деталей // Вестник Полоцкого государственного университета. Серия F. Строительство. Прикладные науки. - 2017. - № 8. - С. 194-199.

10. Yewen T., Douglas M.A., Thabimuthu K.V. $\mathrm{CO}_{2}$ capture using oxygen combustion strategies for natural gas power peants // Fuel. 2002. - V. 81. - № 8. - P. 1007-1016.

11. Wolfgang S. Qualitative and quantitative comparison of two promising oxy-fuel power cycles for $\mathrm{CO}_{2}$ capture: Trans. ASME // Gas Turbines and Power. - 2008. - V. 130 - № 3. - P. 1-11.

12. Siegmund C.W., Turner D.W. $\mathrm{NO}_{\mathrm{x}}$ emissions from industrial boilers: potential control methods // Combustion. - 1973. - V. 45. - № 4. P. $126-132$.

13. Shooter D., Brimblecombe P. Air quality indexing // International Journal of Environment and Pollution. - 2009. - V. 36. - P. 1-3.

14. Дронченко, В.А. Рециклинг жидких производственных отходов, содержащих нефтепродукты // Ресурсосберегающие и экологически чистые технологии: Труды второй научно-технической конференции / под ред. А.И. Свириденка. - Гродно, 1997. T. 2. - C. 308-311.

15. Barancucov M., Dronchenko V. Methods for re-use of waste metalworking faculties at an engineering plant // European and
NatioTal dimension in research: Materials of junior researches' IV conf. - P. 3. - Novopolotsk: PSU, 2012. - P. 65-67.

16. Шерман Ф. Эмульсии. - Л.: Изд-во «Химия», 1972. - 448 с.

17. Дронченко В.А. Получение мелкодисперсной эмульсии на основе нефтесодержащих отходов и ее утилизация // Вестник Брестского государственного технического университета. Машиностроение. - 2017. - № 4 (106). - С. 51-54.

18. Gopal E.S.R. Rheology of Emulsions. - Oxford: Pergamon Press, 1963. $-130 \mathrm{p}$

19. Batsiukov A., Dronchenko V. Determination experimental study of the water content effection in emulsion on its stability // European and National dimension in research: Materials of junior researches V conf. - P. 3. - Novopolotsk: Polotsk State University, 2013. P. $150-153$.

20. Chen D., Sharma S.K., Mudhoo A. Handbook on applications of ultrasound. - New York: Taylor \& Francis Group, LLC, 2012. $118 \mathrm{p}$.

21. Sangave P.C., Pandit A.B. Ultrasound and enzyme assisted biodegradation of distillery waste water // Journal of Environmental Management. - 2017. - № 80. - P. 36-46.

22. Continuous contact and contamination-free ultrasonic emulsification a useful tool for pharmaceutical development and production S. Freitas, G. Hielscher, H.P. Merkle, B. Gander // Ultrasonics Sonochemistry. - 2006. - V.13. - № 1. - P. 76-85.

23. Utilization of electromagnetic and acoustic irradiation in enhancing heterogeneous catalytic reactions / B. Toukoniity, J.P. Mikkola, D.Y. Murzin, T. Salmi // Trends in Chemical Engineering. - 2008. № 11. - P. 1544-1545.

24. Garcia-Lopez A., Sinha Enhanced D.N. Acoustic separation of oilwater emulsion in resonant cavities // Acoustics Journal. - 2008. № 1. - P. 66-71.

Поступила: 13.11 .2018 г.

\section{Информация об авторах}

Иванов В.П., доктор технических наук, профессор, профессор кафедры автомобильного транспорта Полоцкого государственного университета.

Дронченко В.A., старший преподаватель кафедры технологии и оборудования машиностроительного производства Полоцкого государственного университета.

Вигерина T.B., кандидат технических наук, доцент, заведующая кафедрой автомобильного транспорта Полоцкого государственного университета.

Пилипенко C.B., кандидат технических наук, доцент кафедры автомобильного транспорта Полоцкого государственного университета. 


\title{
DISPOSAL OF OIL-CONTAINING WASTEWATER BY EMULSIFICATION AND BURNING
}

\author{
Vladimir P. Ivanov ${ }^{1}$, \\ ivprem@tut.by \\ Vladimir A. Dronchenko', \\ v.dronchenko@psu.by \\ Tatiana V. Vigerina ${ }^{1}$, \\ t.vigerina@psu.by \\ Stanislav V. Pilipenko1, \\ 44-08@mail.ru \\ 1 Polotsk State University, \\ 29, Blokhin avenue, Novopolotsk, 211440, Belarus.
}

The relevance of the work is caused by the need to develop technology and appropriate equipment for disposal of oily wastewater that contain solutions of technical detergents, with the exception of their accumulation in significant volumes in the conditions of individual repair enterprises of medium and low power.

The aim of the work is to eliminate contamination of soil and water basin with oily wastewater with solutions of technical detergents, reduce the share of emissions of harmful substances into the environment during the disposal of the considered waste in industrial boilers.

Methods: theoretical studies of burning oily wastewater, with the inclusion of solutions of technical detergents; experimental studies of thermal processing of this type of pollutants by burning them with natural gas (or furnace fuel) on an operating industrial steam boiler, with a nominal steam production of $6,5 \mathrm{t} / \mathrm{h}$.

Results. The authors have developed and proposed to use the efficient (from an environmental and economic point of view) technology and equipment for storing and treating waste water with oily waste and its subsequent utilization, by burning together with natural gas (or furnace fuel), in the existing industrial steam boiler. The presence of water in the fuel (about $10 \%$ ) increases the efficiency of its combustion, while reducing emissions of nitrogen oxides into the environment. The authors studied the features of the transformation mechanisms that occur during formation of water-fuel emulsion droplets and their subsequent combustion. The use of the energy source separated from the oil-containing waste water allows reducing the consumption of boiler fuel by $3-5 \%$.

\section{Key words:}

Oily wastewater, emulsification, utilization, incineration, emission to the environment.

\section{REFERENCES}

1. Mazumder D., Mukherjee S. Treatment of Automobile Service Station Wastewater by Coagulation and Activated Sludge Process international. Journal of Environmental Science and Development, 2011, vol. 2, no. 1, pp. 64-69

2. Syed S.A.S., Yi W., Song H, Sheng S., Jun X. Thermochemical processing of sewage sludge to energy and fuel: Fundamentals, challenges and considerations. Renewable and Sustainable Energy Review, 2017, no. 80, pp. 888-913.

3. Abdul R., Vineet S.S., Jun He., Wafa D., Dionysios D.D., Wei W., Ming Z. Opportunities and challenges in sustainable treatment and resource reuse of sewage sludge. Chemical Engineering Journal, 2018, no. 337, pp. 616-641.

4. Telnov N.F. Ochistka mashin i voprosy ekologii [Cleaning machines and environmental issues]. Mechanization and electrification of agriculture, 1996, no. 4, pp. 36-41.

5. Dronchenko V.A. Using the waste of repair production as technological materials. Proceedings of GOSNITI, 2017, vol. 126 , pp. 117-120. In Rus.

6. Zaneti R.N., Etchepare R., Rubio J. Car wash wastewater treatment and water reuse - a case study. Water Science \& Technology, 2013 , no. 67.1 , pp. $82-86$.

7. Almeida C.M.V.B., Borges D., Bonilla S.H., Giannetti B.F. Identifying improvements in water management of bus-washing stations in Brazil. Resources, Conservation and Recycling, 2010, no. 54 (11), pp. 821-831.

8. Anderson J., Adin A., Crook J., Davis C., Hultquist R., Jimenez C. Climbing the ladder: a step by step approach to international guidelines for water recycling. Water Science and Technology, 2001, no. $43(10)$, pp. 1-8.

9. Dronchenko V.A., Semenov V.I. Protection of the environment from the harmful effects of waste solutions formed during the submersible cleaning of machines and parts. Bulletin of Polotsk State University. Series: Building. Applied Science, 2017, no. 8, pp. 194-199. In Rus.

10. Yewen T., Douglas M.A., Thabimuthu K.V. $\mathrm{CO}_{2}$ capture using oxygen combustion strategies for natural gas power peants. Fuel, 2002, vol. 81, no. 8, pp. 1007-1016.

11. Wolfgang S. Qualitative and quantitative comparison of two promising oxy-fuel power cycles for $\mathrm{CO}_{2}$ capture: Trans. ASME. Gas Turbines and Power, 2008, vol. 130, no. 3, pp. 1-11.

12. Siegmund C.W., Turner D.W. $\mathrm{NO}_{\mathrm{x}}$ emissions from industrial boilers: potential control methods. Combustion, 1973, vol. 45, no. 4, pp. 126-132.

13. Shooter D., Brimblecombe P. Air quality indexing. International Journal of Environment and Pollution, 2009, vol. 36, pp. 1-3.

14. Dronchenko V.A. Retsikling zhidkikh proizvodstvennykh otkhodov, soderzhashchikh nefteprodukty [Recycling of liquid industrial waste containing petroleum products]. Resursosberegayushchie $i$ ekologicheski chistye tekhnologii. Trudy vtoroy nauchnotekhnichechkoy konferentsii [Resource-saving and environmentally friendly technologies. Proc. of the second scientific and technical conference conference]. Ed. by A.I. Sviridenka. Grodno, 1997. Vol. 2, pp. 308-311.

15. Barancucov M., Dronchenko V. Methods for re-use of waste metalworking faculties at an engineering plant. European and Natiomal dimension in research: Materialsof junior researches' IV conf. P. 3. Novopolotsk, Polotsk State University, 2012. pp. 65-67.

16. Sherman F. Emulsii [Emulsions]. Leningrad, Khimiya Publ., 1972. $448 \mathrm{p}$.

17. Dronchenko V.A. Getting a fine emulsion based on oily waste and its disposal. Bulletin of Brest State Technical University. Engineering, 2017, no. 4 (106), pp. 51-54. In Rus.

18. Gopal E.S.R. Rheology of Emulsions. Oxford, Pergamon Press, 1963. $130 \mathrm{p}$.

19. Batsiukov A., Dronchenko V. Determination experimental study of the water content effection in emulsion on its stability. European and 
National dimension in research: Materials of junior researches $V$ conf. P. 3. Novopolotsk, Polotsk State University, 2013. pp. 150-153.

20. Chen D., Sharma S.K., Mudhoo A. Handbook on applications of ultrasound. New York, Taylor \& Francis Group, LLC, 2012. 118 p.

21. Sangave P.C., Pandit A.B. Ultrasound and enzyme assisted biodegradation of distillery waste water. Journal of Environmental Management, 2017, no 80, pp. 36-46.

22. Freitas S., Hielscher G., Merkle H.P., Gander B. Continuous contact and contamination-free ultrasonic emulsification a useful tool for pharmaceutical development and production. Ultrasonics Sonochemistry, 2006, vol. 13, no. 1, pp. 76-85.

\section{Information about the authors}

Vladimir P. Ivanov, Dr. Sc., professor, Polotsk State University.

Vladimir A. Dronchenko, senior lecturer, Polotsk State University.

Tatiana V. Vigerina, Cand. Sc., associate professor, Polotsk State University.

Stanislav V. Pilipenko, Cand. Sc., associate professor, Polotsk State University.
23. Toukoniity B., Mikkola J.P., Murzin D.Y., Salmi T. Utilization of electromagnetic and acoustic irradiation in enhancing heterogeneous catalytic reactions. Trends in Chemical Engineering, 2008, no. 11, pp. 1544-1545.

24. Garcia-Lopez A., Sinha D.N. Enhanced acoustic separation of oilwater emulsion in resonant cavities. Acoustics Journal, 2008, no. 1, pp. 66-71.

Received: 13 November 2018 